\title{
Mechanical Characterization of a New Architectural Concrete with Glass-Recycled Aggregate
}

\author{
Bernardo Tamayo-García, Albert Albareda-Valls *, Alicia Rivera-Rogel and Cossima Cornado \\ Department of Technology in Architecture, School of Architecture, Polytechnic University of Catalonia, \\ Av. Diagonal 649, 08034 Barcelona, Spain; bernardotamayog@gmail.com (B.T.-G.); \\ alicia.rivera.rogel@gmail.com (A.R.-R.); cossima.cornado@upc.edu (C.C.) \\ * Correspondence: albert.albareda@upc.edu; Tel.: +34-639-523-624
}

Received: 1 May 2019; Accepted: 11 June 2019; Published: 14 June 2019

\begin{abstract}
Concrete is a material which is widely used in architecture, not only for structural purposes but also for architectural elements for its versatility and excellent performance. However, the manufacturing of this material as a mixture of water, cement, and fine and coarse aggregate comes with a high environmental cost, such as gas emissions, among other things. This is the reason why different alternatives are being proposed in order to replace coarse aggregates with other recycled materials, as it is one of the less sustainable components of the mixture in terms of extraction. One of these alternatives is recycled glass coming from drinking bottles, crushed into small grains and mixed in the same proportions as regular aggregates. This study proposes the mechanical characterization of a new architectural concrete mixture by using white Lafarge cement and glass-recycled aggregates; this proposed concrete is made especially for architectural elements like façade panels, rather than structural elements. The mechanical evaluation of this new material is done through a set of experimental tests under compression and also bending, comparing three different ratios of glass aggregate in the mixture.
\end{abstract}

Keywords: recycled aggregates; glass; white concrete; architectural concrete

\section{Introduction}

Concrete is a widely used material in architecture under all shapes and mixtures due to its evident versatility and enhanced mechanical performance. Additionally, it is a relatively low-cost material when comparing with its global performance and durability. During the last century, the global raise of industrialization and urbanization has led to a massive use of concrete for both structural and architectural purposes. Therefore, the consumption of natural aggregates for the mixture has also been increased, since it represents up to $60 \%$ or $75 \%$ of the total volume [1]. The extraction of natural aggregates has serious environmental consequences, from the single alteration of the soil up to greenhouse gas emissions [2,3]. This is the reason why alternative, recycled materials are being sought as a substitute for coarse aggregates, as a priority for sustainable construction. One of these alternatives is recycled glass grains.

Different studies have been carried out about the use of recycled aggregates derived from waste glass for specific concrete mixtures. Glass is a highly recyclable material with many possibilities for reuse, especially as aggregate in concrete mixtures. Among its other interesting properties, recycled glass shows excellent resistance to abrasion [4-6]. According to [7], the reuse of glass for concrete started in the year 1963, with the first experimental campaign. Subsequently, different research has been carried out using glass as fine aggregate in order to describe its behavior and ability to enhance or be harmful to the regular properties of concrete [8-12]. Existing studies and campaigns focus on the mechanical properties of the final mixture, by replacing thick aggregates with recycled glass grains; 
most of these studies conclude that there is a loss of resistance when compared with regular concrete, although this decrement is clearly non-significant $[13,14]$. However, the influence of proportions (the ratio of recycled glass to coarse aggregate) of the final mixture is not still clear. Needless to say, the percentage of recycled aggregate has a direct influence on strength and on the final appearance of the obtained material. The higher the ratio of glass grains in the mixture, the more intense the color. When dealing with structural elements, it is clear that maintaining strength is the main focus; however, when glass-recycled concrete is thought of for other architectural purposes like façade panels or interior walls, final appearance may be more relevant rather than strength.

This research proposes an analysis of a new architectural concrete, thought of for non-structural purposes, by carrying out experimental tests only from a mechanical point of view. This new concrete is formed by glass-recycled grains as an alternative for coarse aggregates, and it is analyzed by replacing different proportions of aggregate in the mixture to obtain different results. The glass grains which are considered in this study mainly come from recycled drinking bottles provided by Camacho Recycling S.L. Glass aggregates, which are mixed with constant granulometry in the study, with particles between 4 and $8 \mathrm{~mm}$, initially chosen in green color in order to provide a new texture for architectural purposes. In order to highlight the color, white cement BL II/A-L 42.5R provided by Lafarge has also been used for the paste due to its high whiteness index. The mechanical properties of this cement are very interesting, it reaches a full resistance of $42.5 \mathrm{MPa}$ at 28 days.

Among all possible applications, there are structural and non-structural elements. The most interesting ones belong to the second group, like, for example, the case of thin concrete panels for façades: pieces of $1.0 \times 3.0 \mathrm{~m}$ height with a thickness of $5 \mathrm{~cm}$ are suitable for ventilated façades. Figure 1a shows the basic deflection of a panel like the ones proposed for façades, caused by wind forces acting uniformly from outside. Figure $1 \mathrm{~b}$ illustrates an estimated view of a full façade solved with these proposed recycled concrete panels.

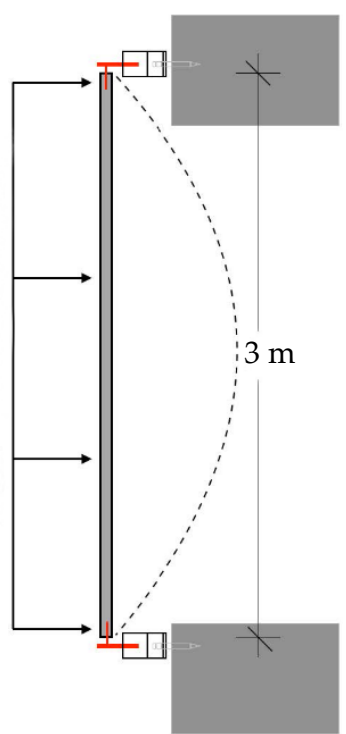

(a)

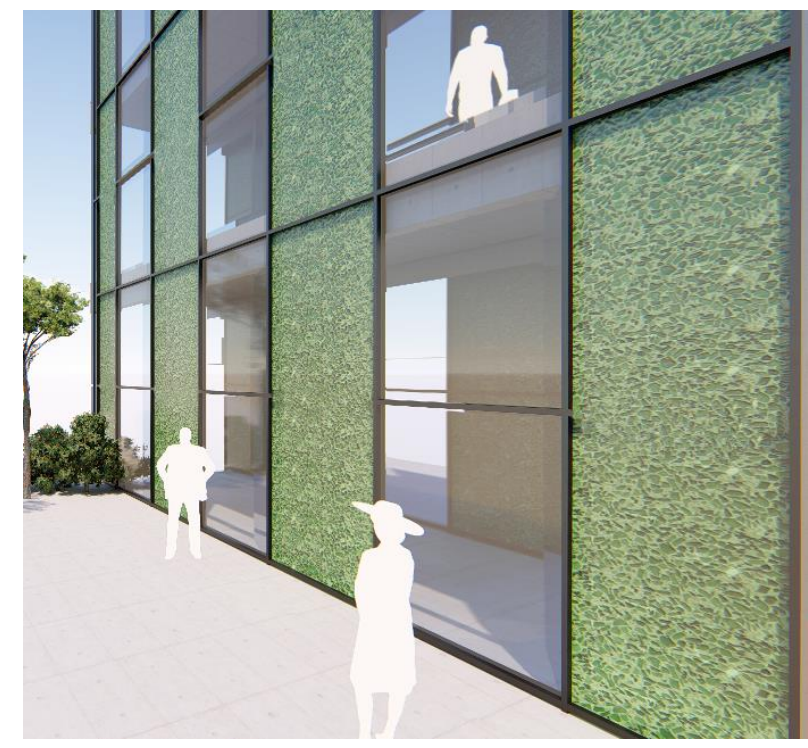

(b)

Figure 1. Possible applications. (a) Wind distributed loads along the $3 \mathrm{~m}$ height; (b) Ventilated façade.

In order to characterize glass-recycled concrete for architectural applications, like thin panels or walls, it is necessary to describe its behavior under compression and also bending, according to the structural behaviors in these cases. The final proportions of coarse glass aggregates in the mixture not only have a crucial influence on the aesthetics of the texture, but also on the mechanical response of the material. One of the main objectives of this research is to describe the influence of the amount of glass grains on the global mechanical response by analyzing the structural behavior with the same ratio of 
recycled aggregates as the one recommended in regular concrete: a double ratio and a triple ratio of recycled glass aggregates.

\section{Experimental Campaign}

The experimental campaign was carried out in the Laboratory of Materials (EPSEB) of the Polytechnic University of Catalonia (UPC). Three cylindrical specimens $(30 \mathrm{~cm} \times 15 \mathrm{~cm})$ and three rectangular specimens $(60 \mathrm{~cm} \times 15 \mathrm{~cm} \times 5 \mathrm{~cm})$ were used in order to determine the response under compression and bending, taking for comparison a C-25 concrete. In order to describe the influence of the amount of glass when replacing traditional granite aggregates, at least two different scenarios were considered regarding the proportion of aggregates: the first ( 1 in Table 1), according to the recommended specifications for the mixture provided by Lafarge (see Table 6 ), the second ( 2 in Table 1) with two times the recommended amount of coarse aggregate, in recycled glass; and the third ( 3 in Table 1) with three times the amount of aggregate in the mixture. When subjected to bending, specimens were bent by adding synthetic polypropylene fibers in the mixture when needed. The experiment was divided into two different phases (compression and bending), all tested at the age of 14 days. Three different specimens were tested for each proportion of aggregates (groups 1, 2 and 3 of specimens) in order to obtain mean and feasible values. The features and proportions of specimens used in the campaign are shown in Table 1.

Table 1. Tested specimens.

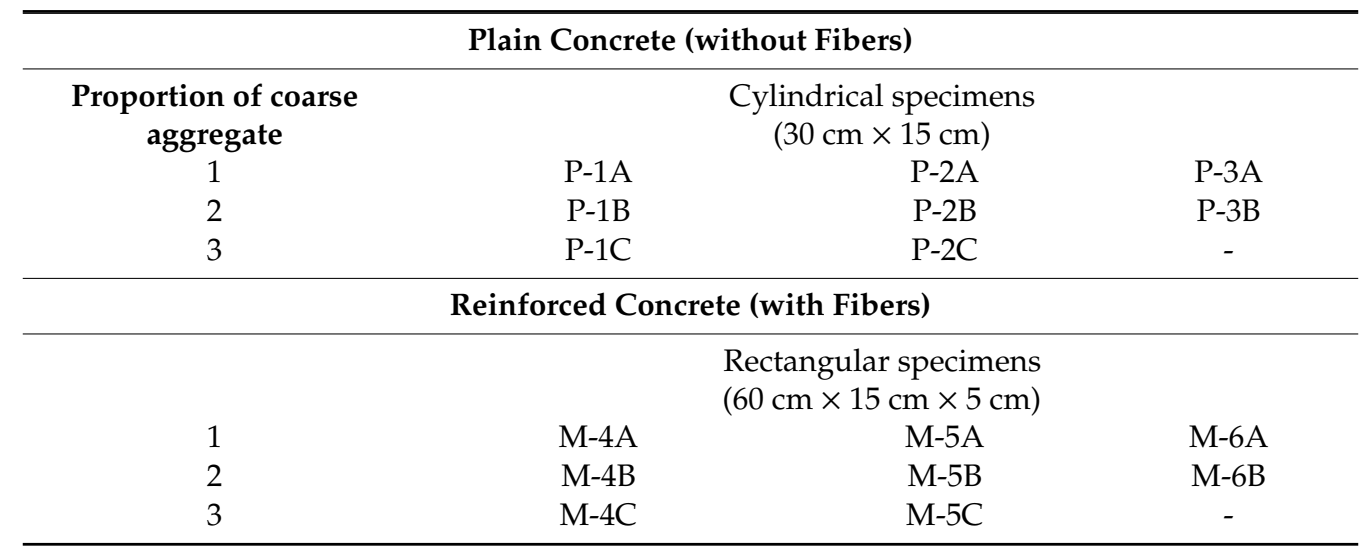

Specific details and properties of mentioned specimens are discussed below, regarding material properties, proportions and manufacturing process.

\subsection{Materials}

Six different components are combined in a traditional mixture of concrete: water, fine aggregate (sand), cement, coarse aggregate (recycled glass) and polypropylene fibers. The first four were considered constant for all specimens, while the last two were varied in the parametric campaign. Tap drinking water, natural sand (with a maximum granulometry of $2 \mathrm{~mm}$ ) and white cement BL II/A-L $42.5 \mathrm{R}$ from Lafarge has been used for the mixture. Table 2 summarizes the main properties of this cement [15].

Coarse aggregates were replaced by glass recycled grains with a constant granulometry (between 4 and $8 \mathrm{~mm}$ ) and color (dark green), a product provided by Camacho Recycling S.L. This material offers interesting properties such as durability, high strength under compression and high resistance under low temperatures (frost). Table 3 shows the main properties [16].

Table 4 shows the granulometric analysis according to ISO Standard 3310.1 [16]. 
Table 2. Cement properties according to Lafarge.

\begin{tabular}{|c|c|}
\hline \multicolumn{2}{|c|}{ White Cement BL II/A-L 42.5R } \\
\hline Clinker & $80-94 \%$ \\
\hline Limestone & $6-20 \%$ \\
\hline Minor components & $0-5 \%$ \\
\hline \multicolumn{2}{|c|}{ Chemical demands } \\
\hline Sulphate & $\leq 4.0 \%$ \\
\hline Chloride & $\leq 0.1 \%$ \\
\hline Water-soluble chrome & $\leq 2 \mathrm{ppm}$ \\
\hline \multicolumn{2}{|c|}{ Mechanical demands } \\
\hline 2-day compressive strength & $\geq 20.0 \mathrm{Mpa}$ \\
\hline 28-day compressive strength & $\geq 42.5 \mathrm{Mpa}$ \\
\hline \multicolumn{2}{|c|}{ Physical requirements } \\
\hline Start of setting & $\geq 60 \mathrm{~min}$ \\
\hline Expansion (Le Chatelier) & $\leq 10 \mathrm{~mm}$ \\
\hline
\end{tabular}

Table 3. Glass recycled properties according to Camacho Recycling S.L.

\begin{tabular}{lcclcc}
\hline \multicolumn{3}{c}{ Chemical Composition } & \multicolumn{3}{c}{ Physical Characteristic } \\
\hline $\mathrm{SiO}_{2}$ & 70.00 & $74 \%$ & Color & \multicolumn{2}{c}{ Green } \\
$\mathrm{Na}_{2} \mathrm{O}$ & 12.00 & $14 \%$ & Hardness & \multicolumn{2}{c}{$6 / 7 \mathrm{Mohs}$} \\
$\mathrm{CaO}$ & 7.00 & $11 \%$ & Specific weight & $2.60 \mathrm{~g} / \mathrm{cm}^{3}$ & \\
$\mathrm{MgO}$ & 1.00 & $4 \%$ & & Non-magnetic metals & $<5 \mathrm{gr} / \mathrm{Tn}$. \\
$\mathrm{Al}_{2} \mathrm{O}_{3}$ & 0.5 & $3 \%$ & & Magnetic metals & 0 gr./Tn \\
$\mathrm{MnO}$ & 0 & $1 \%$ & Impurities & & \\
$\mathrm{FeO} / \mathrm{Fe}_{2} \mathrm{O}_{3}$ & 0.010 & $1 \%$ & & Infusible & $<25 \mathrm{gr} / \mathrm{Tn}$ \\
$\mathrm{K}_{2} \mathrm{O}$ & 0.20 & $0.90 \%$ & & & \\
\hline
\end{tabular}

Table 4. Granulometric analysis.

\begin{tabular}{cc}
\hline Mesh Size (mm) & Quantity (\%) \\
\hline$>8.0$ & 10.0 Max. \\
$<4.0$ & 10.0 Max. \\
\hline
\end{tabular}

Finally, SikaFiber polypropylene fibers were chosen as a reinforcement for pieces subjected to bending. The mixture with these fibers avoids three-dimensional micro cracking by plastic shrinkage in the drying process and by temperature in the hardening phase. According to Sika recommendations, the mixture has to be done during 3 and $5 \mathrm{~min}$ for a correct and complete interaction with the paste. Among the set of significant advantages of using these fibers, there is the fact of their being stainless, resistant to alkalis, and having a very good appearance. Table 5 shows the main properties of these fibers [17].

Table 5. Fiber properties according to Sika.

\begin{tabular}{lc}
\hline & Polypropylene Fiber \\
\hline Material & $100 \%$ virgin polypropylene \\
Color & White \\
Fiber design & Multifilament \\
Length & $19 \mathrm{~mm}$ \\
Thickness of the fiber & 3 denier, $21 \mathrm{microns}$ \\
Ignition point & $350^{\circ} \mathrm{C}$ \\
Stress Resistance & $68.5 \mathrm{PSI}$ \\
Break module & $2.29 \mathrm{Mpa}$ \\
Alkaline resistance & Excellent \\
Thermal conductivity & Low \\
Absorption & $0 \%$ \\
\hline
\end{tabular}


Figure 2 shows the four components used in the specimens.

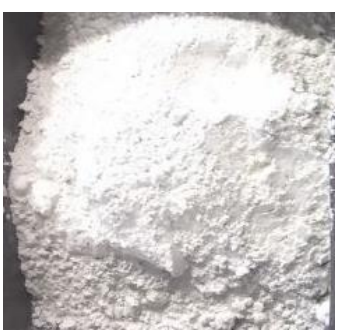

(a)

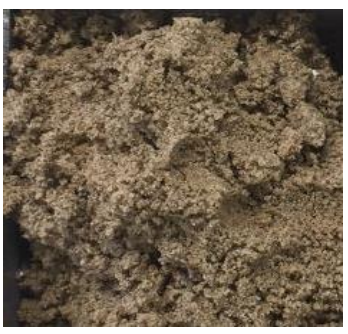

(b)

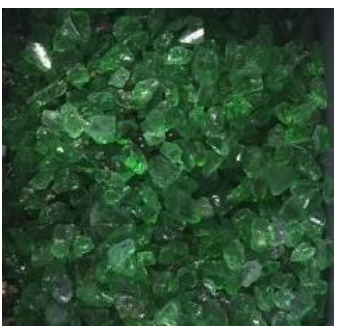

(c)

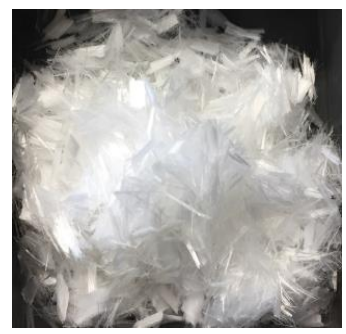

(d)

Figure 2. Components used in the experimental campaign. (a) Cement; (b) Fine aggregate; (c) Coarse aggregate (recycled glass); (d) Fibers.

\subsection{Mixture Proportions}

Mixture proportions were varied, starting with those recommended by Lafarge [15] for a typical C-25 concrete, and doubled and even tripled afterwards. The final proportions were estimated according to each specimen. Table 6 summarizes these proportions (the base unit for calculating the concrete mixture was one liter " $1 \mathrm{~L}$ ").

Table 6. Mixture proportions for C25 concrete.

\begin{tabular}{lccccc}
\hline \multicolumn{5}{c}{ Concrete Mixture Proportions According to Lafarge for C25 Concrete } \\
\hline \multicolumn{1}{c}{ Company Lafarge } & $\begin{array}{c}\text { Cement } \\
\mathbf{( k g )}\end{array}$ & $\begin{array}{c}\text { Fine } \\
\text { Aggregate (L) }\end{array}$ & $\begin{array}{c}\text { Coarse Aggregate } \\
\text { (L) }\end{array}$ & $\begin{array}{c}\text { Water } \\
\text { (L) }\end{array}$ & $\begin{array}{c}\text { Fibers } \\
\text { (box) }\end{array}$ \\
\cline { 2 - 6 } & $\mathbf{6 . 2 5}$ & $\mathbf{8 . 7 5}$ & $\mathbf{1 3 . 7 5}$ & $\mathbf{3}$ & - \\
\hline $\begin{array}{l}\text { Concrete without fibers } \\
\text { Recommended percentage of } \\
\text { coarse aggregate }\end{array}$ & 6.25 & 8.75 & 13.75 & 3 & - \\
\hline $\begin{array}{l}\text { Concrete with fibers } \\
\text { Double percentage of } \\
\text { coarse aggregate }\end{array}$ & 6.25 & 8.75 & 27.5 & 3 & $1 / 4$ \\
\hline
\end{tabular}

Water/cement ratio was kept constant at 0.48 in all specimens.

\subsection{Process of Manufacturing the Specimens}

A total of 16 tests were carried out: eight under compression and eight under bending. Different nomenclatures were chosen to identify the specimens, based on the amount of pre-mixed glass as coarse aggregate, both for cylindrical $(\mathrm{P})$ and rectangular $(\mathrm{M})$ specimens. Figure 3 shows the process of manufacturing the specimens.

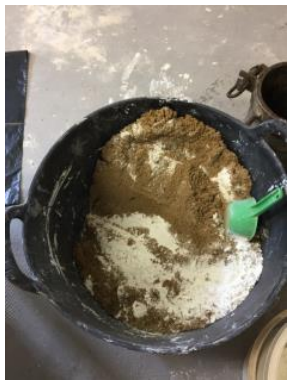

(a)

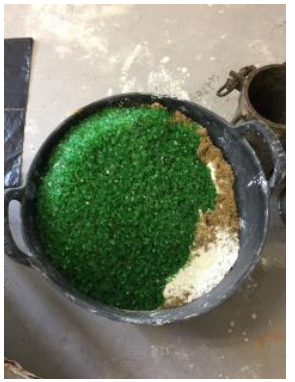

(b)

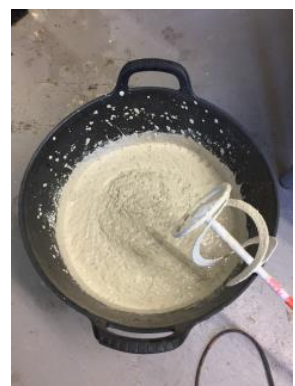

(c)

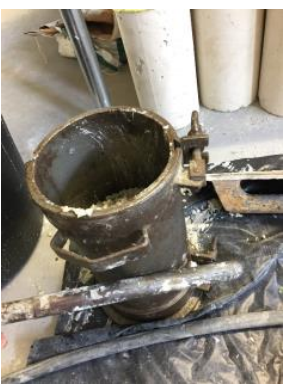

(d)

Figure 3. Process of manufacturing the specimens. (a) Dry mixture of components; (b) addition of the glass grains and water; (c) mixture with mortar mixer $550 \mathrm{~W}$ and 0/2600 rpm; (d) compaction with a rod. 
A similar procedure was used for both rectangular and cylindrical specimens; however, in the second group polypropylene reinforcing fibers were also added to the mixture. In order to maximize the performance of the reinforcements, they were oriented and located inside the elements in different layers.

\subsection{Curing Process}

For a proper curing process, after $24 \mathrm{~h}$ of setting the wet paste, the specimens were removed from the molds and stored in the humid chamber. During the following 13 days, the specimens were dried there, under a relative humidity between $90 \%$ and $93 \%$ (see Figure 4 ).

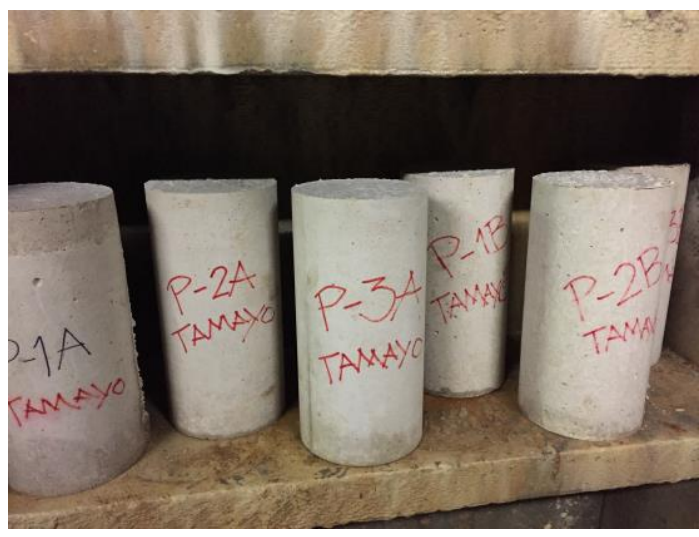

(a)

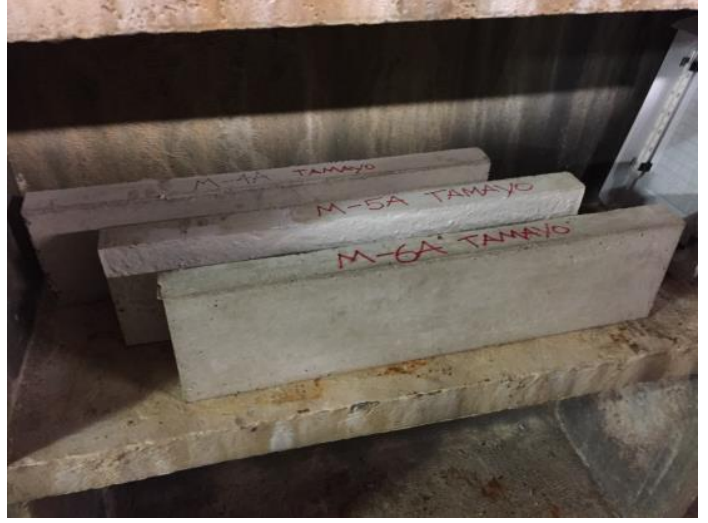

(b)

Figure 4. Curing process. (a) Cylindrical specimens; (b) Rectangular specimens.

After the curing period, specimens were cut $24 \mathrm{~h}$ before with the help of a machine, with the purpose of lowering between $5 \mathrm{~mm}$ and $10 \mathrm{~mm}$ of the upper face to get a smooth and, above all, a flat surface. The upper face was treated with a protection based on sulfur in order to assure a proper loading on the top and the best distribution of stresses during the application of load (see Figure 5).

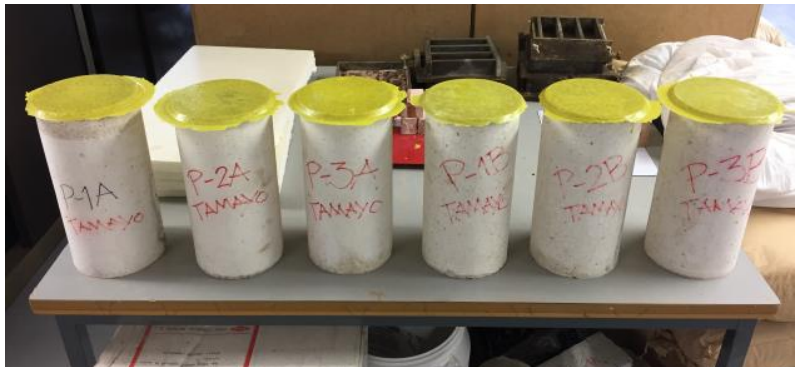

(a)

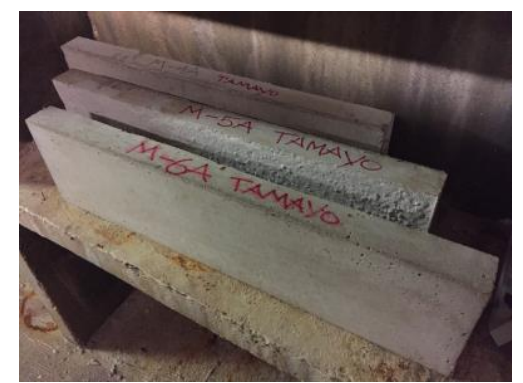

(b)

Figure 5. Final preparation of specimens. (a) Cylindrical specimens; (b) Rectangular specimens.

\section{Results from Experimental Tests}

\subsection{Compression Tests}

The procedure established by the ASTM (American Society for Testing and Materials o ASTM International) C39/C39M 2016 Standard test method for the compressive strength of cylindrical concrete specimens was used in this study [18].

Eight different tests were carried out with two different proportions of recycled glass as coarse aggregate in the mixture. The final objective of these tests was to evaluate the suitability of the proposed concrete for structural purposes or other architectural elements (see Figure 6). 


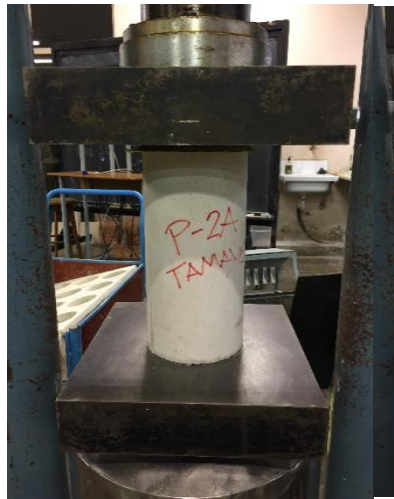

(a)

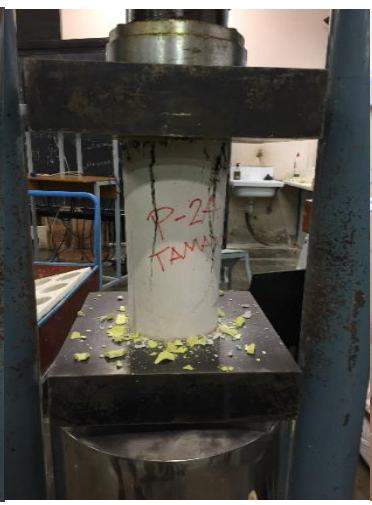

(b)

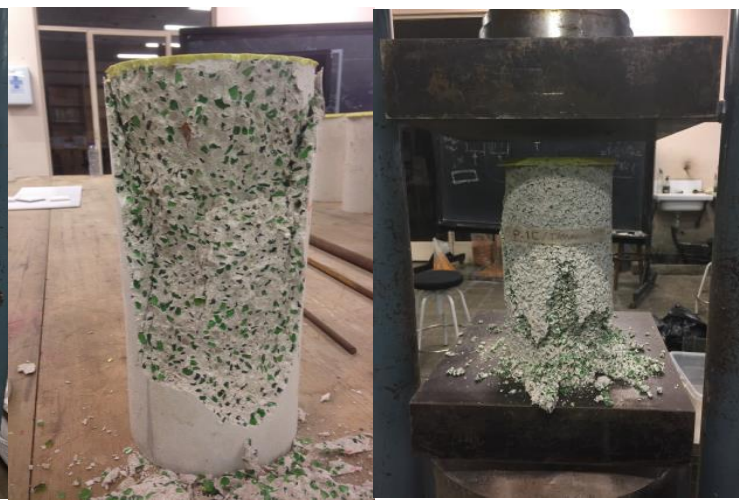

(c)

(d)

Figure 6. Tested Specimens under compression: $(\mathbf{a}, \mathbf{b})$ regular amount of glass; (c) double amount of glass, (d) triple amount of glass.

Table 7 summarizes the results obtained from compression tests of cylindrical specimens, with two different proportions of glass as coarse aggregate according to Table 1 . The results of specimens ending with A correspond to a proportion of glass equivalent to the one recommended by Lafarge, while those ending with $\mathrm{B}$ correspond to double proportion of glass. The first three outcomes corresponding to specimens P-1A, P-2A and P-3A show a good performance of the proposed concrete under compression, compared with the nominal strength of regular C25 concrete. Concrete specimens with double amount of glass as aggregate derive into a significant decrement of strength, and concrete specimens with a triple amount show almost a third part of total strength; this is the reason why the second and third mixtures are suitable only for architectural applications such as pavements or finishing panels as the ones proposed in this study.

Table 7. Ultimate loads reached from compression tests.

\begin{tabular}{ccc}
\hline Specimen & Ultimate LOAD (Mpa) \\
\hline P-1A & 19.89 \\
P-2A & 25.73 \\
P-3A & 25.26 \\
& Double recycled glass & \\
P-1B & & 18.66 \\
P-2B & & 19.89 \\
P-3B & Triple recycled glass & 19.79 \\
& & 9.99 \\
P-1C & & 9.6 \\
P-2C & &
\end{tabular}

\subsection{Bending Tests}

A single-point load test was used to determine the ultimate bending strength of the proposed rectangular specimens. The two supporting edges were separated by a distance of $45 \mathrm{~cm}$ from each other (see Figure 7) according to the ASTM C 293-02 Standard test method for the flexural strength of concrete using a simple beam with center-point loading [19]. Once the specimen was placed in the correct position the load was applied slowly in the mid-point of the element in order to measure deflections until the collapse. Load-deflection curves were obtained from tests by using extensometers (see Figure 8). 


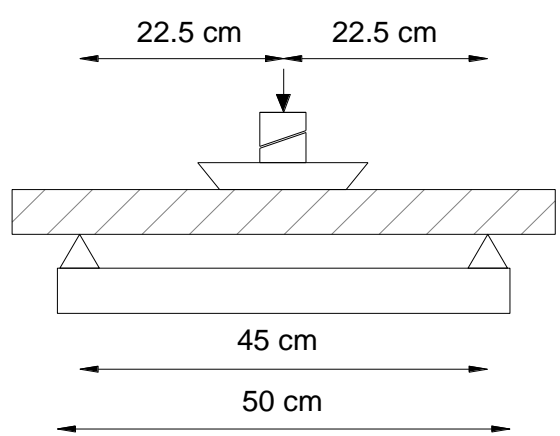

Figure 7. Test scheme for the rupture module.

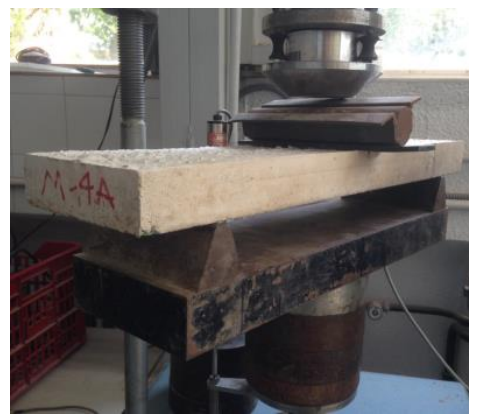

(a)

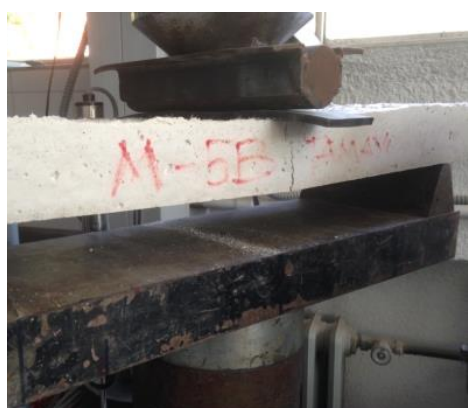

(b)

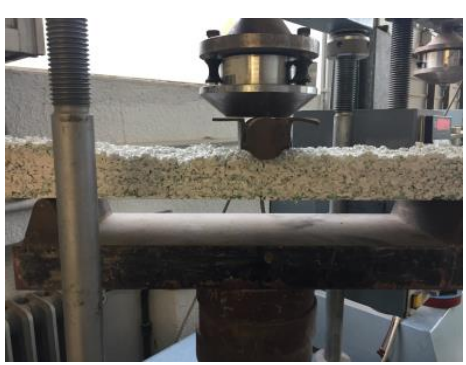

(c)

Figure 8. Specimens subjected to bending tests. (a) recommended proportion; (b) double proportion; (c) triple proportion.

Table 8 shows ultimate loads under bending of the eight tested specimens.

Table 8. Ultimate bending loads.

\begin{tabular}{ccc}
\hline Specimen & Ultimate Load (KN) \\
\hline M-4A & 0.83 \\
M-5A & 0.79 \\
M-6A & Double recycled glass & 0.69 \\
& & 0.69 \\
M-4B & & 0.40 \\
M-5B & & 0.80 \\
M-6B & Triple recycled glass & 0.37 \\
& & 0.44 \\
M-4C & & \\
M-5C & & \\
\hline
\end{tabular}

Figure 9 shows different load-deflection curves obtained from tests.

The tested specimens under bending showed similar values for deflection, independently of the ratios of recycled aggregate, which were in the mixture (see Figure 9). Derived from the results, the specimens showed a sharp rupture after the collapse, independently of the presence of the fibers. A higher amount of recycled coarse aggregate derives into a clear reduction of bending strength, as in case of compression. However, while the trend of the curve of descent of strength depending on the proportion of aggregate in case of specimens under compression was convex, the trend of the curve in case of bending was clearly concave (see Figure 10a,b). This tendency is significant in order to define the suitability of this material for structural purposes. While structural concrete is mainly used for heavy compressed elements, architectural concrete is mainly subjected to uniform loading or lateral forces (see Figure 1). For the first case of structural use, the increment of recycled aggregate derived 
into a dangerous sharp collapse of the specimens (sharp reduction of strength); the mode of collapse occurred also sharply by emulating high-strength concretes.

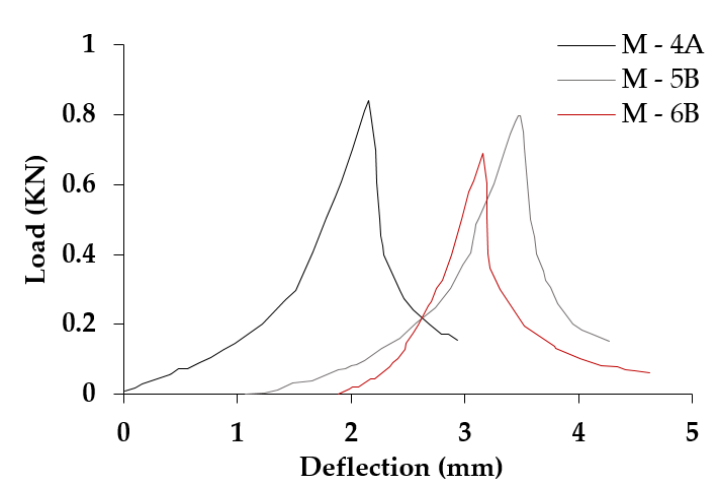

(a)

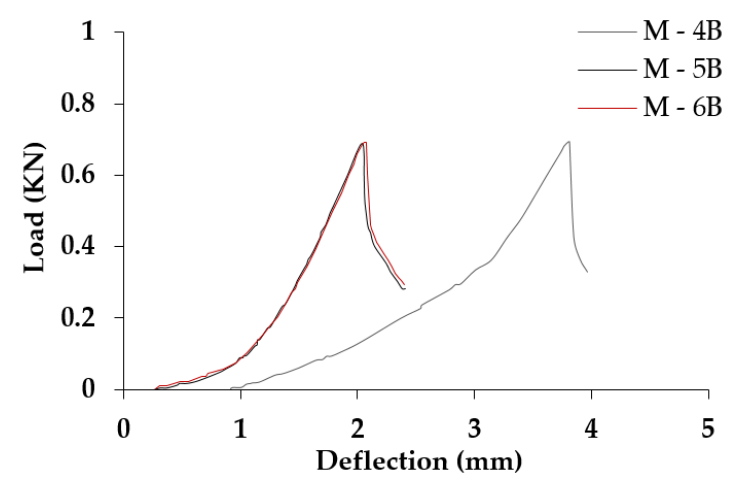

(b)

Figure 9. Load-deflection curves from bending tests (b) double proportion.

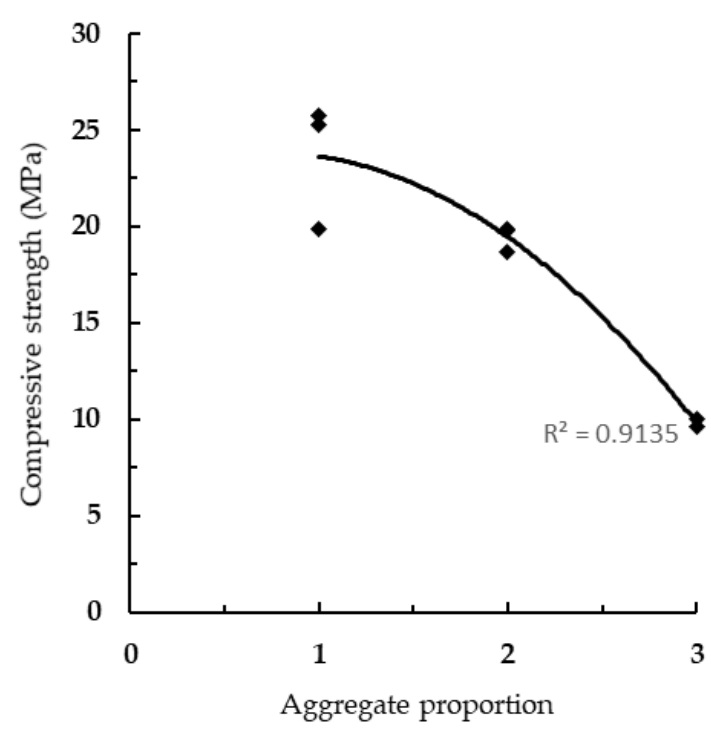

(a)

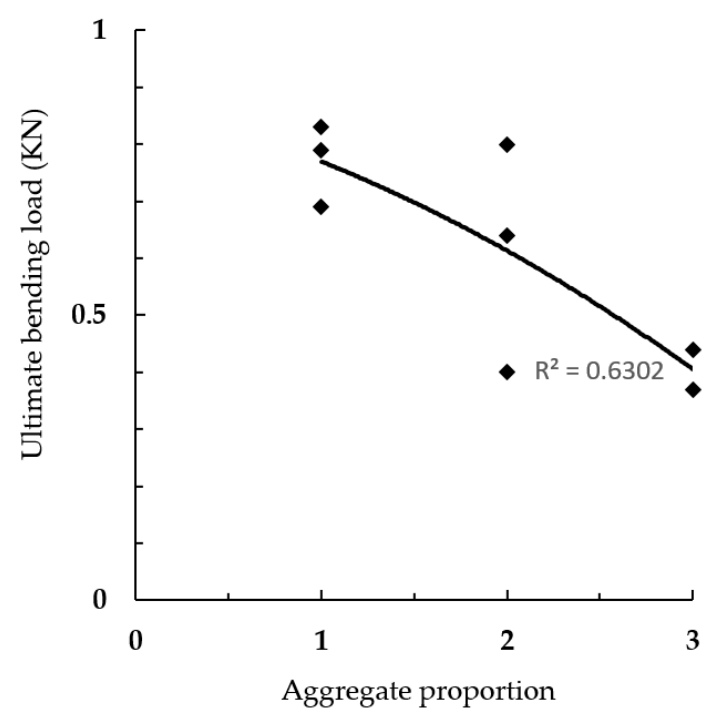

(b)

Figure 10. Strength and load evolution depending on the recycled aggregate proportion. (a) compressive strength; (b) ultimate bending load.

Contrarily, when the concrete was reinforced with fibers and subjected to bending, the descent of strength was less abrupt with stabilizing when the coarse aggregate ratio was three times the recommended one by Lafarge for typical concrete.

Note that specimens with a double ratio of recycled glass aggregate suffered from a significant dispersion in the obtained results, much more so than in other cases. This was caused in part by the reduction of ductility, along with the fact of having double ratio of coarse aggregate. The fragility of specimens with high ratios of glass coarse aggregate derived directly from the reduction of cement inside the mixture (see Figure 8).

\section{Conclusions}

The main conclusion obtained from this research is that the use of recycled-glass as a substitute of coarse aggregate in architectural-oriented concrete is possible from a mechanical point of view. The 
ratio of the aggregate used in the mixture directly affects the final strength of the obtained material, in both assumptions of compression and bending. However, all tested specimens show a minimum level of strength that allows us to use this material for architectural purposes, like façades and walls.

The reduction of strength depending on the replacement amount of coarse aggregate shows a different path for specimens subjected to compression than specimens under bending. In the first group, the reduction of strength occurs much more sharply beyond two times the recommended proportion of coarse aggregate in the mixture.

Additionally, when respecting the recommended ratios of coarse aggregate proposed by Lafarge when replacing for recycled glass aggregates, specimens do not show a significant reduction of the estimated regular compressive strength. This means that this new concrete may even be used for structural purposes with the same requirements of regular concrete, only with specific percentages of glass in the mixture.

Due to the fragile response of those specimens with high ratios of glass recycled aggregates, these mixtures are only suitable for architectural elements like façade panels or walls, mainly subjected to bending and uniform loading thanks to the action of reinforcing fibers. Elements with thicknesses of $4 \mathrm{~cm}$ or thinner are not convenient to be used as panels, since the efficiency of fibers in reinforcing the mixture becomes harder with higher percentages of recycled grains.

Author Contributions: Conceptualization: A.A.-V. and B.T.-G.; Methodology: A.A.-V. and B.T.-G.; Formal Analysis: B.T.-G.; A.A.-V. and C.C.; Investigation: B.T.-G.; A.A.-V.; A.R.-R. and C.C.; Data curation: B.T.-G.; A.R.-R. and C.C.; Writing —original draft: A.R.-R. and A.A.-V.; Writing-review and editing: A.A.-V. and A.R.-R.

Funding: This research received no external funding.

Acknowledgments: The authors like to express gratitude to the companies Camacho Recycling and SIKA S.A.U-Spain by donation of material. Furthermore, Alicia Rivera-Rogel gratefully acknowledges the financial support given by Ecuadorian Government's Secretaría de Educación Superior, Ciencia, Tecnología e Innovación (SENESCYT) through a Ph.D-grant.

Conflicts of Interest: The authors declare no conflict of interest.

\section{References}

1. Kosmatka, S.; Kerkhoff, B.; Panarese, W. Design and Control of Concrete Mixtures, 14th ed.; Pembina Institute: Drayton Valley, AB, Canada, 2002.

2. Winfield, M.S.; Taylor, A. Rebalancing the Load: The Need for an Aggregates Conservation Strategy for Ontario; Pembina Institute for Appropriate, Development: Drayton Valley, AB, Canada, 2005.

3. Abbas, A.; Isgor, O.B.; Razaqpur, A.G.; Fournier, B.; Foo, S. Environmental benefits of green concrete. In Proceedings of the 2006 IEEE EIC Climate Change Conference, Ottawa, ON, Canada, 10-12 May 2006.

4. Dyer, T.; Dhir, R. Chemical reactions of glass cullet used as cement components. J. Mater. Eng. 2001, 13, 412-417. [CrossRef]

5. Shayan, A.; Xu, A. Value-added utilisation of waste glass in concrete. Cem. Concr. Res. 2004, 34, 81-89. [CrossRef]

6. Taha, B.; Nounu, G. Properties of concrete contains mixed colour waste recycled glass as sand and cement replacement. Constr. Build. Mater. 2008, 22, 710-720. [CrossRef]

7. Ling, T.; Poon, C.; Wong, H. Management and recycling of waste glass in concrete products: Current situations in Hong Kong. Resour. Conserv. Recycl. 2013, 70, 25-31. [CrossRef]

8. Shayan, A.; $\mathrm{Xu}, \mathrm{A}$. Performance of glass powder as a pozzolanic material in concrete: A field trial on concrete slabs. Cem. Concr. Res. 2006, 36, 457-468. [CrossRef]

9. Ling, T.; Poon, C.; Kou, S. Cement and concrete composites influence of recycled glass content and curing conditions on the properties of self-compacting concrete after exposure to elevated temperatures. Cem. Concr. Compos. 2012, 2, 265-272. [CrossRef]

10. Afshinnia, K.; Rangaraju, P.R. Impact of combined use of ground glass powder and crushed glass aggregate on selected properties of portland cement concrete. Constr. Build. Mater. 2016, 117, 263-272. [CrossRef]

11. Fathifazl, G.; Abbas, A.; Razaqpur, A.G.; Isgor, O.B.; Fournier, B.; Foo, S. New mixture proportioning method for concrete made with coarse recycled concrete aggregate. J. Mater. Eng. 2009, 21, 601-611. [CrossRef] 
12. Eduardo, A. Mechanical properties modeling of recycled aggregate concrete. Constr. Build. Mater. 2010, 24, 421-430.

13. Canbaz, M. Properties of concrete containing waste glass. Cem. Concr. Compos. 2004, 34, 267-274.

14. Terro, M.J. Properties of concrete made with recycled crushed glass at elevated temperatures. Build. Environ. 2006, 41, 633-639. [CrossRef]

15. Lafarge Holcin. Available online: https://www.lafargeholcim.es/cemento-blanco-productos (accessed on 8 January 2019).

16. Camacho Recycling. Available online: http://www.camachorecycling.es/ (accessed on 13 May 2019).

17. SikaFiber ${ }^{\circledR}$ M-12. Fibras de polipropileno monofi lamento para el refuerzo de hormigones y morteros. Hoja de Datos del Product 2012, 1,3.

18. ASTM C39/C39M-16a. Standard Test. Method for Compressive Strength of Cylindrical Concrete Specimens; ASTM International: West Conshohocken, PA, USA, 2016.

19. ASTM C293/C293M-16. Standard Test. Method for Flexural Strength of Concrete Using Simple Beam with Center-Point Loading; ASTM International: West Conshohocken, PA, USA, 2016.

(C) 2019 by the authors. Licensee MDPI, Basel, Switzerland. This article is an open access article distributed under the terms and conditions of the Creative Commons Attribution (CC BY) license (http://creativecommons.org/licenses/by/4.0/). 